\title{
Review of Recent Developments in Wave Rotor Combustion Technology
}

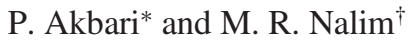 \\ Indiana University-Purdue University at Indianapolis, Indianapolis, Indiana 46202
}

DOI: $10.2514 / 1.34081$

\begin{abstract}
For some decades, efforts have been made to exploit nonsteady combustion and gas dynamic phenomenon. The theoretical potential of nonsteady-flow machines has led to the investigation of various oscillatory flow devices such as pulse detonation engines, wave rotors, pulse jets, and nonsteady ejectors. This paper aims to provide a progress review of past and current research in developing a particular combustion concept: the wave rotor combustor. This pressure-gain combustor appears to have considerable potential to enhance the performance and operating characteristics of gas turbine and jet engines. After attempts in the mid-twentieth century were thwarted by mechanical problems and technical challenges identified herein, recent successes in Switzerland and efforts in the United States benefited from design expertise developed with pressure-exchange wave rotors. The history, potential benefits, past setbacks, and existing challenges and obstacles in developing these nonsteady combustors are reviewed. This review focuses on recent efforts that seek to improve the performance and costs of future propulsion and powergeneration systems.
\end{abstract}

\section{Introduction}

$\mathbf{T}$ HE past century has witnessed many proposed and realized combustion systems to improve the performance, emissions, costs, and operation of combustion engines. Although intermittentcombustion positive-displacement piston engines remain dominant for automobiles, steady-combustion gas turbine engines dominate aircraft propulsion and a growing range of power-generation applications. Intermittent or pulsed combustion devices that do not require positive displacement remain an important possibility for gas turbines and thrust applications. Renewed interest in pulse-jet engines in the form of the pulsed detonation engine (PDE) has heightened awareness of this possibility. Nonsteady-combustion devices have also been commercialized for pulse combustion spray drying, boiler cleaning, fog generation, and home heating [1-ㅜㄹ]

Steady-flow combustion is always accompanied by a loss in stagnation pressure, but nonsteady combustors can produce a pressure rise. Such a system is schematically illustrated in Fig. 1 for a turbofan engine. The pressure-gain combustor replaces the conventional steady-flow combustor and possibly the high-pressure spool or some costly turbomachinery stages.

Various approaches have been made to devise pressure-gain combustors, seeking improved fuel efficiency and power output or thrust or other benefits. Positive-displacement free-piston devices were naturally among the first contenders as a topping cycle in a gas turbine [4], similar to turbo-compound engines in which the piston output is dominant. Although prototypes were built and some designs commercialized [5], the complexity and weight of such combined turbine and piston engines have prevented wide application. Unvalved or check-valved pulse combustors in gas turbines and for jet propulsion also received early attention, but yielded limited cycle efficiency improvement [6], raising concerns of excess noise and vibration. Pulse-jet engines and pulse furnaces have been

Presented as Paper 5055 at the 43rd AIAA/ASME/SAE/ASEE Joint Propulsion Conference \& Exhibit, Cincinnati, OH, 8-11 July 2007; received 16 August 2007; revision received 4 February 2009; accepted for publication 4 February 2009. Copyright $\odot 2009$ by the American Institute of Aeronautics and Astronautics, Inc. All rights reserved. Copies of this paper may be made for personal or internal use, on condition that the copier pay the $\$ 10.00$ percopy fee to the Copyright Clearance Center, Inc., 222 Rosewood Drive, Danvers, MA 01923; include the code 0748-4658/09 and $\$ 10.00$ in correspondence with the CCC.

${ }^{*}$ Research Associate, Department of Mechanical Engineering. Member AIAA.

${ }^{\dagger}$ Associate Professor, Department of Mechanical Engineering. Associate Fellow AIAA. mass-produced, and pulse combustion gas turbines have been demonstrated [3]. More recently, significant developments in pulse detonation engines for propulsion have also prompted attempts to create "hybrid" gas turbine engines using detonative combustion. These developments are briefly reviewed in Sec. II.B as a prelude to the review of the wave rotor combustor.

This review paper is in four sections. In Sec. II, the relative thermodynamic benefit of constant-volume combustion is explained, and a brief description of previous efforts and methods to achieve such a combustion process is provided. In Sec. III, the reader is introduced to the wave rotor and its use as a combustor. Sec. IV provides a historical review and status update of research and development activities related to wave rotor combustion technology, with emphasis on recent achievements and future development needs.

\section{Pressure-Gain Combustion Benefits and Methods}

\section{A. Constant-Volume Combustion for Gas Turbines}

Some of the earliest gas turbines used pressure generated by confined intermittent combustion. In the early 1900s Holzwarth and Griepe proposed gas turbine designs with nearly constant-volume combustion. In Holzwarth's design [7], multiple combustors are used to create a high-pressure pulsing flow stream. This stream then axially impacts the blades of a turbine wheel. Griepe's design [8] used multiple combustion chambers around the periphery of a radialinflow turbine, but acknowledged ineffective use of wave action in the combustion chamber. Other designs $[\underline{9}, 10]$ sought to improve on thermal efficiency, but no practical gas turbine was commercialized with stationary constant-volume combustors. Challenges reported [ $\underline{8}-11]$ were inefficient flow process and work extraction from combustion gases, idle and part-load performance, low specific power, and cumbersome mechanical components. Meanwhile, gas turbines with simple continuous combustors became enormously successful by improving turbomachinery aerodynamic performance and turbine cooling technology.

Constant-volume combustion followed by full working-gas expansion in a downstream device or flow, and usually preceded by upstream compression, is referred to as the Humphrey thermodynamic cycle $[\underline{12}, \underline{13}]$. This is illustrated in Fig. 2, which compares schematic temperature-entropy $(T-s)$ diagrams of the conventional Brayton engine $\left(1-2-3_{b}-4 b\right)$ and the Humphrey cycle (1-2-3-4) for fixed turbine inlet temperature and compressor discharge pressure. Significant pressure gain $\left(p_{3}>p_{2}\right)$ begets greater turbine power output and higher cycle efficiency for fixed combustion energy input. 


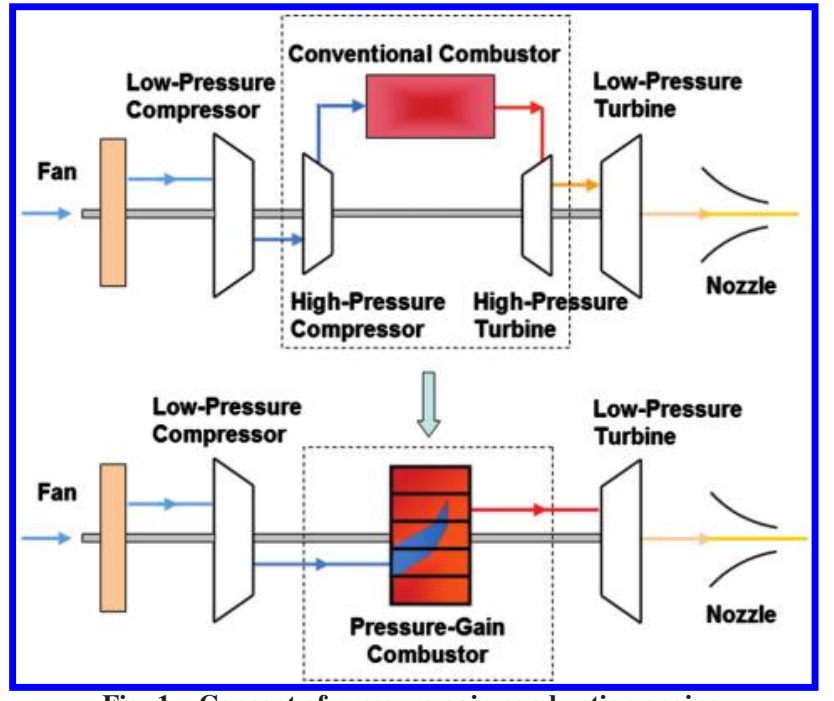

Fig. 1 Concept of pressure-gain combustion engine.

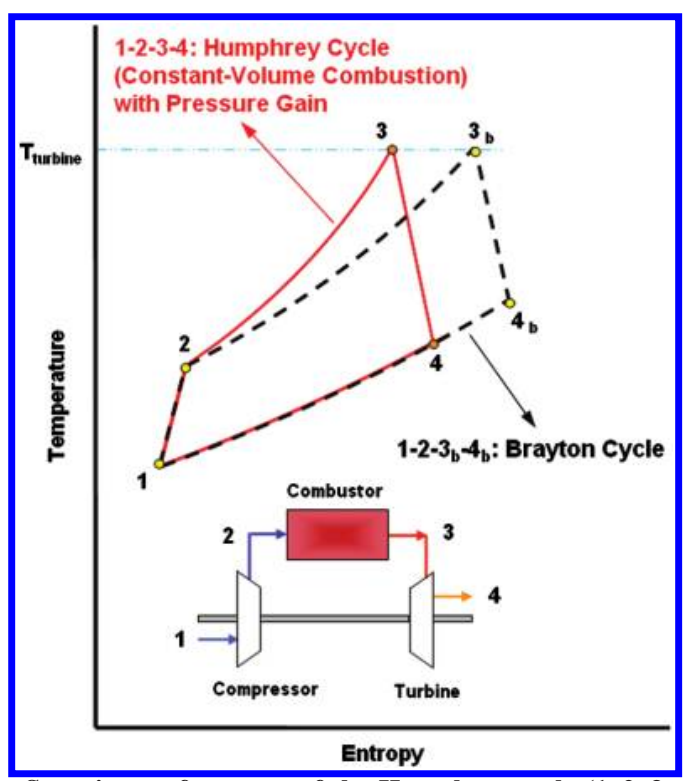

Fig. 2 Superior performance of the Humphrey cycle (1-2-3-4) over the Brayton cycle $\left(1-2-3_{b}-4_{b}\right)$.

It should be noted that the Humphrey cycle may combine open and closed system components, which requires careful accounting of flow work [12].

Comparison of ideal entropy generation during combustion for the two cycles is revealing. Air-standard cycle calculation with a constant specific heat ratio of $\gamma=1.33$ shows the ratio of entropy production for given heat addition (by combustion) between fixed temperatures in the Brayton and Humphrey cycles as

$$
\frac{\Delta s_{2-3}}{\Delta s_{2-3_{b}}}=\left[\int_{2}^{3} c_{v} \frac{\mathrm{d} T}{T}\right] /\left[\int_{2}^{3_{b}} c_{p} \frac{\mathrm{d} T}{T}\right] \approx 0.75
$$

This roughly $25 \%$ ideal reduction in entropy production represents substantial thermodynamic efficiency potential. It enables constantvolume combustion to offer a dramatic improvement even in highly optimized modern gas turbines.

\section{B. Pulse-Jet and Pulse Detonation Engines}

Constant-volume combustion can be achieved by either deflagrative or detonative combustion modes. Deflagrative combustion in a closed chamber at roughly constant volume is commonly achieved in piston engines. The self-pressurization of confined deflagrative combustion was exploited by pulse-jet engines with mechanical or aerodynamic valving. More recently, detonations that achieve locally near-constant-volume combustion in an openoutflow chamber enabled PDEs [14,15]. In a typical PDE, detonable mixtures of fuel and air are admitted into open-ended tube(s) and ignited, generating a detonation that provides a pulse of pressure and thrust. Following early work on single-tube PDE, recent work has focused on multiple-tube PDE designs $[16,17]$ that provide a more continuous but still unsteady flow output. Among various possible configurations, the rotary-valved multiple-tube PDE proposed by Bussing [18] has several stationary detonation chambers in a circular array coupled to a common air-fuel duct via a rotary valve. This arrangement allows some of the PDE chambers to be filled while detonation occurs in other PDE chambers.

Multiple-tube PDEs have been also considered for performance improvement of aircraft jet engines that include turbomachinery, for example, turbofan engines, creating hybrid PDE systems. In proposals to replace the high-pressure core of a turbine engine with a PDE, as schematically illustrated in Fig. 1, the goal is to provide higher turbine pressure from pressure-gain combustion. Although analytical $[13,19]$ and simplified numerical simulations of PDE flows [20] predict high performance improvements for moderate supersonic flight speeds, detailed multidimensional modeling [21] and experimental efforts [22] indicate substantial flow losses and a complex interaction of highly nonsteady PDEs and steady-flow turbomachinery. The turbulence-inducing obstacles needed for deflagration-to-detonation transition (DDT) and periodically stagnating duct flows represent flow losses that can diminish or wipe out performance gains. Strong pressure pulses at the exit of PDE tubes subject turbine blades to highly unsteady flow [20], and narrow mixture detonability limits result in peak gas temperature beyond turbine design conditions. Several practical issues including highfrequency pulsed ignition and valving, mechanical integration, noise, and unsteady turbomachinery interactions must be addressed [17]. Some of these challenges can be overcome by the wave rotor as a nonsteady-flow machine that can be integrated more closely with turbomachinery flows, as explained in the following.

\section{Wave Rotor Approach to Pressure-Gain Combustion}

Wave rotor technology offers a method of sequencing nonsteady confined combustion in multiple chambers to generate pressure gain with relatively steady inflow and outflow suitable for integration with inlets, nozzles, or turbomachinery. A wave rotor consists of a rotating drum as schematically seen in Fig. 3, with multiple gas channels around the circumference, usually oriented axially. The drum rotates between two stationary endplates, each of which has ports or manifolds at different pressures, controlling the fluid flow through the channels. Through rotation, the channel ends are periodically connected to ports located on the stationary endplates. The sudden opening or closing of the rotating channel to the stationary ports initiates gas-dynamic compression and expansion waves within the channels. With proper timing of the port interactions, these waves effect pressure and energy exchange between fluids, dynamically, that is, without pressure equilibration. To minimize leakage, the gap between the end plates and the rotor has to be uniformly very small, for example, less than a hundredth of the channel height [23], avoiding contact under all operating and thermal expansion conditions. Additional sealing may be used [24]. The rotor is driven by a belt or an electrical motor, or may run freely with precise aerodynamic design. The power required to spin the rotor at a correct speed overcoming rotor windage and friction is relatively low [25].

A variety of applications have elicited different wave rotor configurations distinguished by the number and azimuthal location of the wave rotor ports and different heat addition or gas usage schemes. Wave rotors were initially developed as dynamic pressure exchangers for gas turbines, and other early pressure-exchange applications included [26] supercharging of piston engines, air conditioning, and hypersonic wind tunnel gas compression. Significant commercial success was attained by the Comprex ${ }^{\circledR}$ supercharger for diesel car engines (Fig. 3). A comprehensive review of pressure-exchange wave rotors for different applications is available 


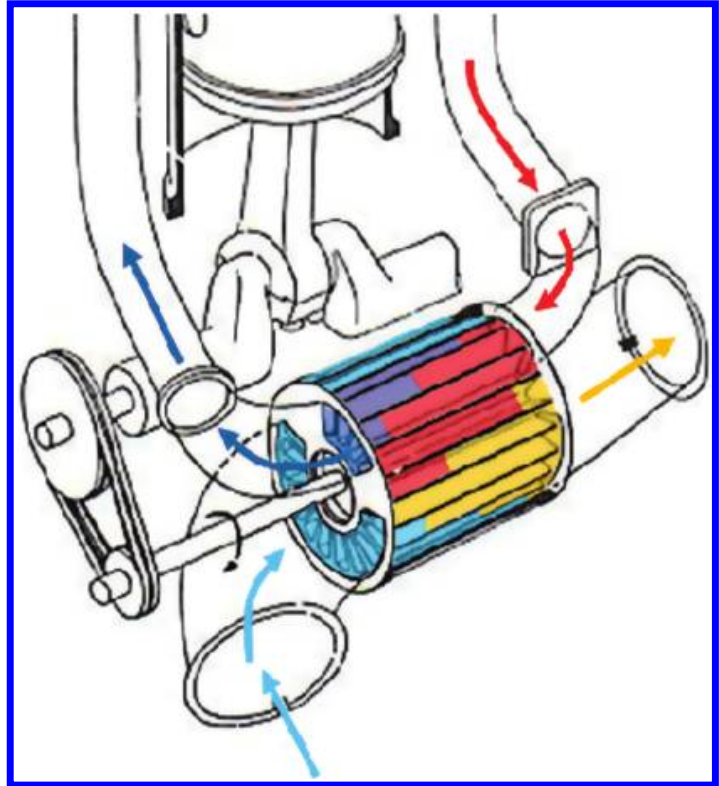

Fig. 3 Schematic exploded view of the Comprex supercharger wave rotor [25].

in [27]. Although the primary focus of the present review is the use of wave rotors as pressure-gain combustors, a brief description of pressure-exchange wave rotors is provided in the following.

\section{A. Pressure-Exchange Wave Rotor: Basic Machine}

Pressure-exchange wave rotors are designed to exchange energy between fluids at different pressure levels. Compression and expansion within the rotor channels are accomplished by gasdynamic waves, rather than a mechanical medium like a piston or blade. Although the energy exchange process within the rotor channels is fundamentally oscillatory, the flows in the ports are continuous and relatively steady. To illustrate wave rotor operation, an example of a four-port pressure-exchange wave rotor integrated into a gas turbine cycle is considered here.

Pressure-exchange wave rotors enhance the performance of conventional gas turbines by acting as a topping spool to increase the overall cycle pressure ratio without increasing the turbine inlet temperature. Figure 4 schematically shows the interfacing of the four-port pressure-exchange wave rotor into a gas turbine cycle as a topping unit. In this arrangement, air from the upstream compressor

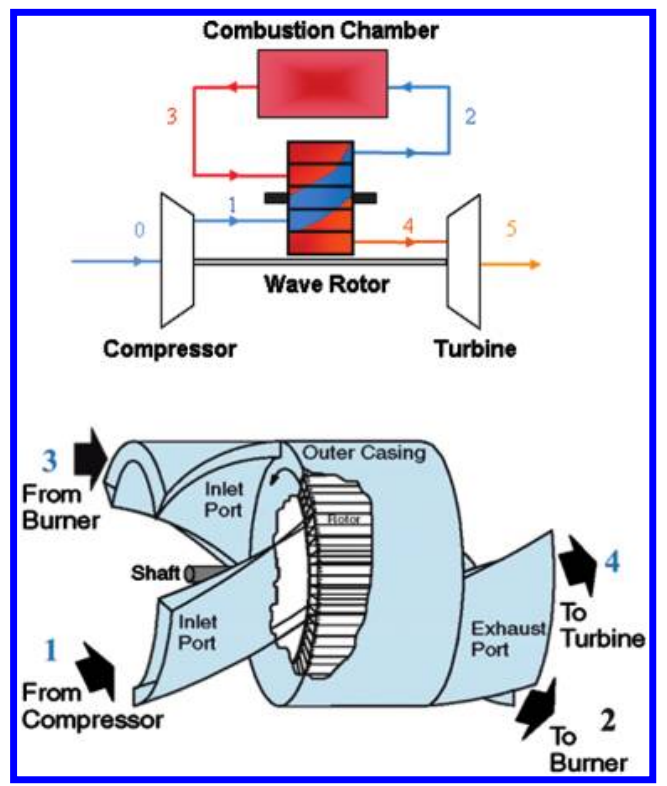

Fig. 4 Schematic (top) of a gas turbine topped by a four-port pressureexchange wave rotor (bottom) [28]. enters the wave rotor at port 1 and is further compressed inside the wave rotor by wave action. The compressed air leaves the wave rotor at port 2 , and discharges into the combustion chamber. Combustion takes place at a higher pressure and temperature than in a conventional gas turbine engine with the same compressor exit state. The hot gas leaving the combustion chamber enters the wave rotor at port 3 , and partially expands inside the wave rotor by expansion waves. The expanded burned gas leaves the wave rotor at port 4, entering the turbine at the same inlet temperature as the corresponding conventional engine but at higher pressure. Consequently, more work can be produced from the turbine in the cycle topped with the wave rotor, increasing engine thermal efficiency and output power. This outcome has been demonstrated both theoretically [28-30] and experimentally $[23,31]$. However, the complex ducting to and from the combustor and additional weight may be seen as drawbacks to this approach [32,33]. The aerodynamic and mechanical design of such transition ducts have been investigated for accommodation of circumferential variation in flow properties across the ports of particular cycle designs [32-35].

\section{B. Wave Rotor Combustors}

The performance of a gas turbine or ramjet engine can be improved by using the many channels of a wave rotor as combustion chambers operating similar to a PDE but automatically synchronized by rotation for valving, ignition, and combustion [36]. In comparison with the pressure-exchanger topping approach, the high-pressure ducting and associated high temperatures are avoided. The pressure rise in such a "wave rotor combustor" is achieved by the combination of pressure-wave compression and expansion and confined combustion within the rotor channels. This configuration presents many new possibilities and some challenges to provide the on-rotor fueling, ignition, and combustion that are discussed next.

The wave rotor combustor, illustrated in Fig. 5, has geometric features and gas-dynamic nonsteady flow much like a pressureexchange wave rotors. In addition, each of the channels act as an individual combustion chamber, which periodically charges and discharges as it rotates past the partial-annular inlet and outlet ports, with the end walls functioning as the inlet and exit valves. Combustion within the channels requires a method of introducing fuel and a method of ignition that will ensure rapid combustion of all fuel. For example, the air inlet duct may incorporate fuel nozzles to disperse fuel in controlled increments, and igniters may be located at one or both end plates. Only one inlet and one outlet port and one continuously-firing stationary igniter are minimally required, but some designs may use two outlet ports at different pressures for complete evacuation of the channels. The inlet port allows premixed air-fuel mixtures to flow sequentially into the rotating channels as they come into alignment with the port. After discharge and recharge, both ends of each channel are closed, and combustion occurs at a

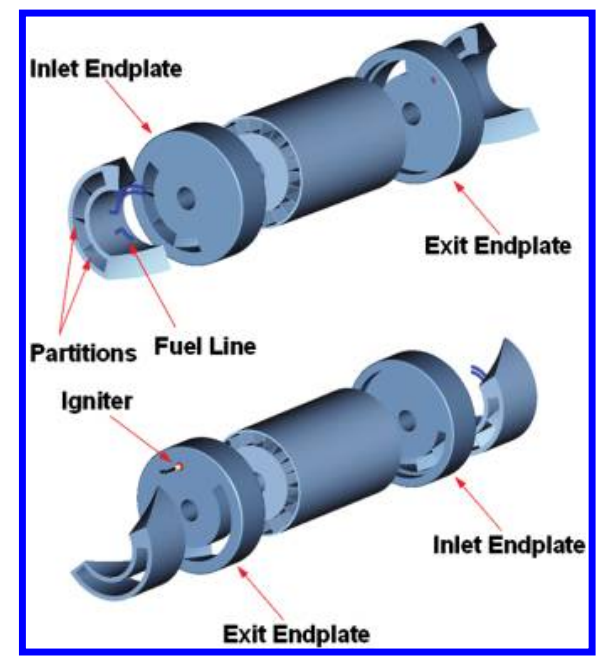

Fig. 5 Schematic configuration of a wave rotor combustion from inlet (top) and exit (bottom) views. 
nearly constant-volume condition that generates pressure rise. Thus, the outlet port discharges the burned gas at a higher pressure than the inlet flow due to the confined-combustion process, even if deflarative. Compared with pressure-exchange topping cycles and other methods that increase overall pressure ratio, judicious mixture stratification and deflagration in the wave rotor combustor allow lower combustion temperatures. With rapid combustion and gasdynamic quenching, residence time at peak temperature is also relatively short, limiting nitrogen oxide $\left(\mathrm{NO}_{x}\right)$ emissions $[37,38]$.

\section{Integration of Wave Rotor Combustor into Gas Turbine or Ramjet Engine}

From both aerodynamic and mechanical points of view, there are several advantages of the wave rotor configuration. Rotation of channels into alignment with transition ducts accomplishes effective high-frequency low-loss valving, with no obstruction in the open state and limited leakage in the closed state. The circumferential position of each channel dictates its phase in the cycle. At any instant, several rotating channels receive and discharge flow, each presenting the same flow properties to the local region of appropriate transition ducts, which will thus have relatively steady (but nonuniform) flows. This fundamental synchronicity of cycle phase and circumferential position also allows a simple nonpulsed ignition system such as a hot gas jet or recirculation tube. It also enables stratified fuel-air mixture in the channel to be created by providing multiple steady-flow fuel injectors in the inlet duct (which may be partitioned accordingly) or in the end walls. Thus no oscillating parts or subsystems are introduced, and the rotor remains the only moving part.

In most applications, the nonsteadiness of velocity in the transition ducts will be relatively small. Reports of previous successful applications of wave rotor technology $[26,31]$ and wave rotor combustor testing $[38,39]$ have expressed no particular concerns on this issue. However, pressure fluctuations may be transmitted from strong waves such as a detonation-driven blast wave exiting directly. In comparison with a stationary PDE, a wave rotor with even such a blast wave was predicted to have only one-fourth the temporal velocity fluctuation at any location in the exit duct [40]. Further, the pressure of the blast wave is spatially limited and could be specially treated. Nevertheless, the spatial distortions that remain must be considered for engine integration. For transition of nonuniform hot gas flow to an annular turbine or nozzle inlet, ducting from the partial-annular wave rotor ports must be designed to redistribute momentum and energy appropriately. The design of such transition ducts for pressure-exchange wave rotors can be adapted for wave rotor combustors $[32,33]$. Other advantages and challenges of wave rotor combustors will become apparent from the following discussions.

\section{Internal Working Principle of the Wave Rotor Combustor}

The typical inflow-outflow gas-dynamic processes occurring inside the rotor channels are shown in Fig. 6, a schematic, developed (unwrapped) view of the wave rotor combüstor, illustrating sequential purging, filling, and firing.The circumferential motion of the rotor channels is represented on paper by a vertical upward translatory motion, and channels appear horizontal, showing sequential purging, filling, and firing. At any moment, several combustors (more than shown) receive flow from the compressor, and several deliver flow to the turbine, while others are closed and firing under volumetric confinement. Although the wave rotor is intrinsically a cyclic, nonsteady device, the relatively large number of channels (typically 20-50) and the automatic phasing of internal events with rotation result in nearly continuous flow observed at any fixed location in the ducting and in the connected turbine and compressor. The instantaneous gas distribution is illustrated in a few of the many channels, and the gas dynamics in the remainder are illustrated as a "wave diagram" by simplified wave trajectories. The combustion details, minor reflected waves, and complex flow patterns are omitted.

The simplest wave rotor combustor cycle involves three steps: the filling of the device with a combustible mixture, the initiation and

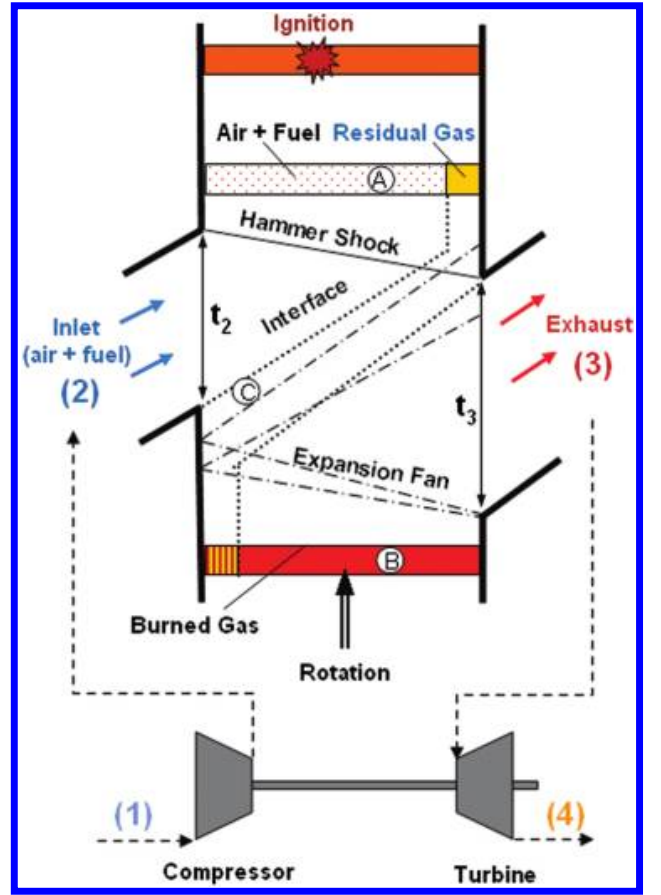

Fig. 6 Wave pattern in a developed view of the combustion wave rotor.

completion of the combustion, and finally, the exhaust of highpressure products into the turbine. The gas-dynamic processes of compression, shock, and expansion waves play a vital role in the wave rotor combustor's functionality. The exhaust and inlet ports are located such that waves generated by the exhaust process drive the inlet process, in a manner specific to the wave rotor. Opening the exhaust port creates an expansion wave that accelerates burned gas at state B to leave the channels at state 3 . The expansion wave arrives at the opposite end when the channel becomes exposed to the inlet port and draws in purge air and combustible mixture (state 2). While the filling process continues, the scavenging of purge air or burned gas through the exit port is stopped by closing the exhaust port, generating a ram compressive wave or "hammer shock." Fresh airfuel mixture (state A) and possibly some purge air and/or residual gas are trapped in the channel and are favorably compressed by the hammer shock wave that propagates backward toward the inlet wall. The inlet port is sized to be closed upon arrival of the shock wave. With both ends of the channel closed, combustion is initiated by an igniter (not shown). The combustion process under constant-volume condition increases the pressure and temperature in the channel significantly to state $\mathrm{B}$, completing the cycle. Residual gas is avoided in some designs [38] by using a second exhaust port at lower pressure to completely evacuate the channel. The features of the cycle results in a relatively uniform inflow and outflow, significant pressure gain, and overall temperature ratio that is compatible with the gas turbine engine requirements. Like most pressure-exchange wave rotors, the wave rotor combustor is a self-cooled machine because the rotor channels are swept alternately by hot and cold fluids. The timeaverage wall temperature is lower than the combustion peak temperature.

Currently, there is limited knowledge of the possible combustion processes in a wave rotor. In principle, both deflagrative and detonative combustion modes can provide confined combustion for wave rotors, creating pressure rise across the channels. A wave rotor combustor must 1) develop and use pressure rapidly enough to minimize losses from heat transfer and leakage, 2) have low weight and volume commensurate with gas turbine or flight application requirements, 3) minimize nitrogen oxide and other emissions, 4) have manageable heat load, and 5) complete combustion in an equitable fraction of the total cycle time. All these requirements demand fast combustion rates. Detonation, although fast, requires particular fuels in limited ranges of stoichiometry and channel width, and its concentrated pressure and momentum may complicate both 
integration with turbomachinery and rotor thermomechanical design for cyclic peak loads and temperatures. The deflagration combustion mode in a wave rotor has been studied both theoretically [37,41,42] and experimentally [38], and the detonation mode theoretically $[40,43]$, anticipating transferability of PDE research. Fast deflagrations may be more desirable than detonations for gas turbine applications and plausibly attainable due to the high inlet turbulence levels and pressure-wave acceleration of the flame.

Combustion initiation may be provided by one or more igniters placed at either the forward or aft end of the channels or both, depending on whether forward or backward or multiple flame propagation is desired. The term "forward-propagating" implies propagation of the flame or detonation from the inlet end toward the exit end. Conversely, "backward-propagating" flame or detonation is initiated by an igniter embedded in the exit end wall as shown in Fig. 5. Each approach may differ in fueling options, ignition options, flame propagation, pollutant formation, discharge flow uniformity, leakage gas, pressure loading, pollutant emissions, and thermal loads. For example, forward-detonation propagation results in direct emanation of a blast wave, whereas the backward-propagating detonation would provide a more uniform exit flow profile and shorter residence time of hot gas. The forward-propagating detonation wave rotor configuration resembles the flowfield of the most typical PDE designs [20], but the wave rotor combustor outflow differs spatially and temporally and includes an exit valve that enables ram compression by a hammer shock. Proposed ignition methods include a sparkplug device, a glow plug, a laser device, a separately fueled prechamber, a cross-fire tube that routes hot combusted gas from a previously burned channel, or a combination of these methods [42]. A cross-fire tube or an end-wall cavity that injects or recirculates hot gas makes the combustion process essentially continuous and self-sustaining [38]. On-rotor igniters switched by wireless or slip contacts would allow for shorter combustion distances and times but have not been developed.

A description of the internal flow and combustion processes based on computer simulation is helpful in visualizing the cycle at a level of detail not easily available from experiments. Figure 7 provides an example of modeling a backward-detonation-propagation cycle with no residual gas and with fuel introduced both by premixing into air in the inlet and by direct injection into the combustion chamber. It is based on a quasi-one-dimensional (Q1-D) gas-dynamic simulation code described later, which uses a simplified model of fuel introduction and combustion. The figure includes computed wave diagrams of nondimensional temperature, pressure (logarithmic), and fuel concentration, and a graph of velocity at the channel inlet (blue line) and exit (red line). The white lines on the sides of the temperature plot represent the portion of the cycle over which the inlet and outlet ports are closed. The sudden closing of the exhaust port results in ram compression of the fresh mixture and air within the channel, doubling charge mass and density. Discernible in the pressure plot of Fig. $\underline{7}$ are the leftward trajectory of the generated hammer shock and its rightward reflection. For reliable ignition from the exit end wall, a direct fuel injector is proposed to create a pilot mixture contiguous with ingested mixture and adjacent to the exit wall (combustible mixture appears red in the fuel fraction plot). A simulated DDT process uses a prescribed deflagration speed and duration. The channel temperature is elevated for only a short part of the cycle, allowing better thermal management and low $\mathrm{NO}_{x}$ emissions potential. The exit velocity profile is relatively less uniform than the inlet but not as skewed as for forward-detonation propagation cycles $[\underline{40}, \underline{44}]$.

\section{Historical Review}

Figure $\underline{8}$ is presented to summarize the known history of the wave rotor research reviewed here and in the literature. It is selfexplanatory, arranged broadly by geography, including both combustion and pressure-exchange applications. This chart indicates significant efforts by various companies and research groups worldwide attempting different applications. It encompasses all wave rotor applications, as context for the following discussion of wave rotor combustors specifically.

The notion of a wave rotor with internal combustion first appeared in the 1950s and significant work resumed in the 1990s, as described in this section. Contemporaneous investigations of other constantvolume or pulsed combustors have also played a role in the evolution of the wave rotor combustor engine concept. In this review, it is intended to summarize these studies, giving more emphasis to recent developments. This review is based mainly on technical documents in the open literature and accessible corporate reports, and it is likely that internal corporate documents exist but are not publicly available. As with any technology development, it is inadvisable to speculate about program management decisions and the motivations of key individuals, despite their historical importance. In assessing the cost/ benefit requirements of different applications, it should be noted that power-generation gas turbines generally value high efficiency and low emissions and have many options to achieve these aims. Aircraft gas turbines value high specific power and efficiency and

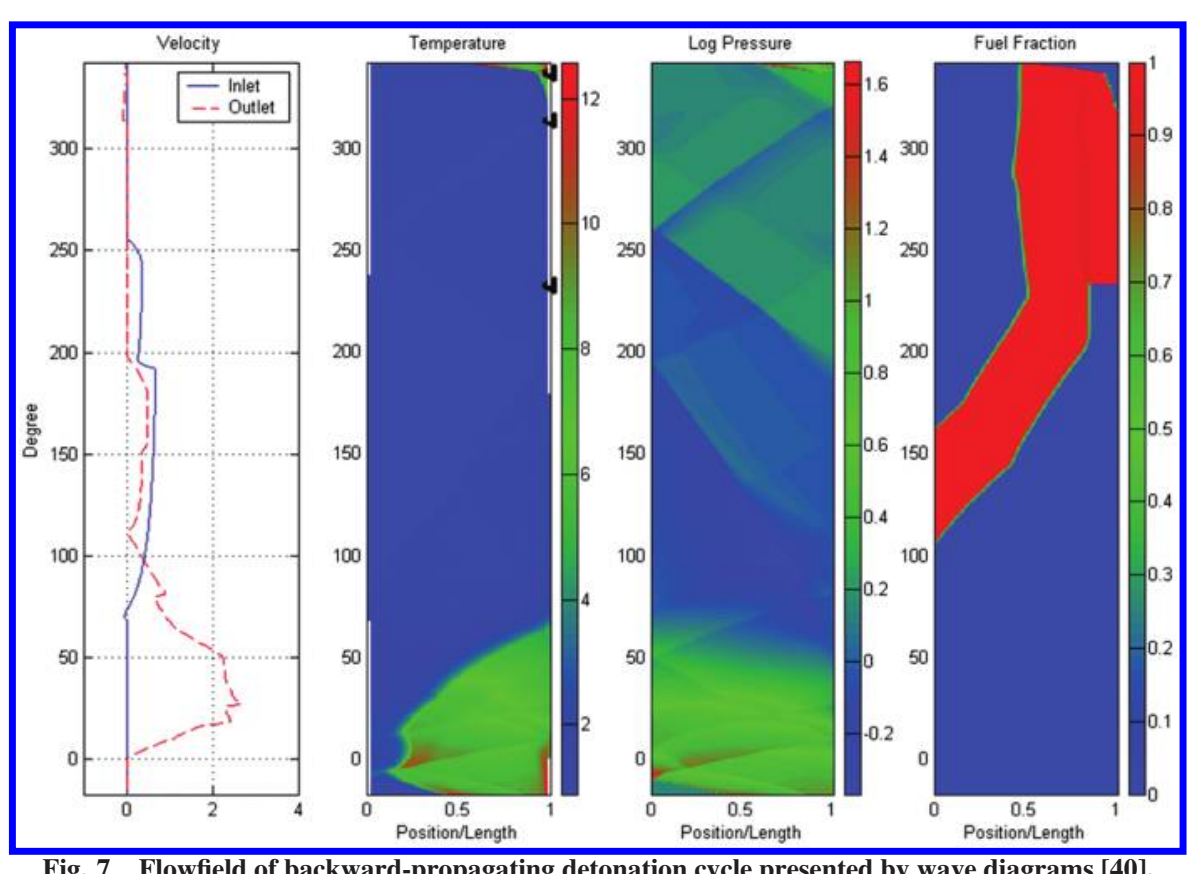

Fig. 7 Flowfield of backward-propagating detonation cycle presented by wave diagrams [ㅇ]. 


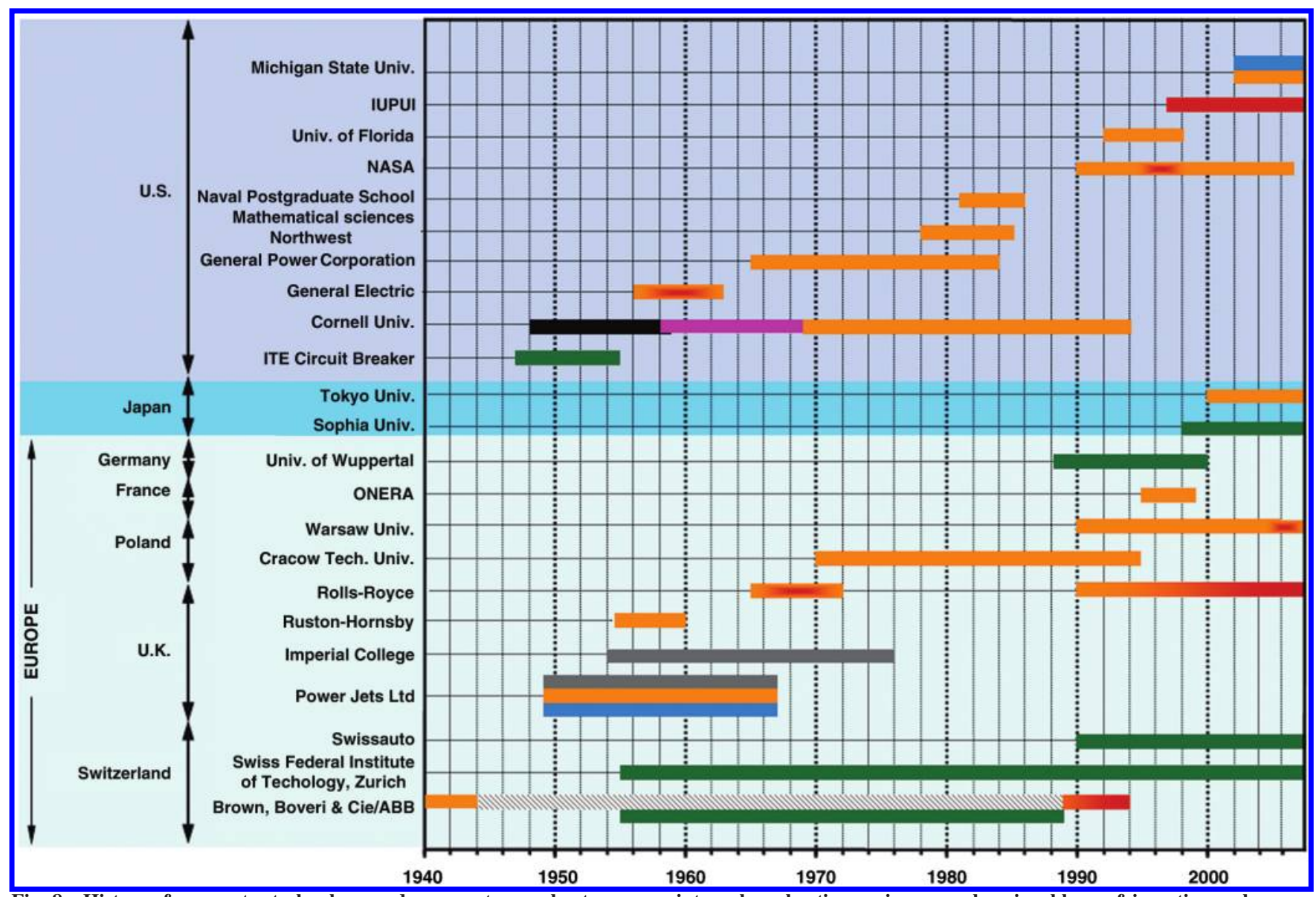

Fig. 8 History of wave rotor technology: red: wave rotor combustor, green: internal combustion engine supercharging, blue: refrigeration cycle, gray: pressure divider and equalizer, pink: wave superheater, black: general applications, and orange: gas turbine application.

have stricter fuel specifications and limits on space, weight, and packaging.

\section{A. Initial Attempts (1948-1958)}

The early twentieth century development of automobiles and airplanes drove the development of pulsed and valved combustion engines of different types, including resonant pulse-jet engines. World War II deployment of the V1 pulse-jet "buzz bomb" was followed by further efforts in wave engines [45]. Lewis is the earliest published proponent of the wave rotor combustor. His 1955 patent [46] invoked gas-dynamic phenomenon to promote the constant-volume combustion process within a wave rotor apparatus. However, some literature $[38,47]$ suggest that this idea may have naturally arisen from the equivalent configurations with rotating or mechanical valving of a stationary drum of combustors, such as described in 1951 by Hertzberg and Logan [48] of Cornell Aeronautical Laboratory, where pressure-exchange wave rotors were also being developed. They attempted sustainable combustion within a single combustion channel of an envisioned stationary multichannel combustion device. Wave motions were controlled by mechanically operated flapper valves, which periodically would open and close at each end of the combustor. Fuel was injected in the combustor to form a combustible mixture in the region adjacent to the exit valve. Reported challenges included thermomechanical limitations related to rotor thermal expansion, flow losses, mixing losses, side-wall overheating, leakage control, opening and closing timing of the valves, and erratic combustion behavior. Shortly after, a similar single-channel wave engine was designed at Rensselaer Polytechnic Institute (RPI) in which the exit valve was replaced by a converging exhaust nozzle to avoid some difficulties of the Hertzberg and Logan engine. Foa [45] reported difficulties in controlling the complex interactions between the shock waves, the fluid flow, and the combustion process inside the modified engine.
Further, the RPI engine would experience considerable drop in performance for small deviations from an optimum shock wave strength. Without exit valving, the achievement of this optimum in practice seemed unlikely.

Conceptual and feasibility studies of combustion in a rotating device in the late 1950s [49-51] includes a comprehensive study by Klapproth of the General Electric Company (GE) and Goldstein of NASA of the performance estimation of shaft-power gas turbine plants and jet engines by employing wave rotor combustors [52]. The study considered stationary power turbines (with and without regeneration), and turbojets and ramjets operating at various flight speeds. Compared with corresponding baseline engines, the results predicted improved efficiency for the modified engines in certain operating conditions. The authors raised concerns about 1) ignition delay and timing problems with lean air-fuel mixtures, and 2) offdesign rotational speed estimation for different fuel inputs and pressure outputs. Klapproth and NASA [53] apparently motivated $\mathrm{GE}$ to invest in wave rotor technology, as described next.

\section{B. General Electric Company (1956-1963)}

GE began investigations on both pressure-exchange wave rotors and wave rotor combustors between 1956 and 1963. The Ohio branch of GE focused mostly on designing and testing two experimental four-port pressure-exchange wave rotors with straight and curved channels (producing shaft work and, therefore, called a wave engine). Meanwhile, its California advanced propulsion systems operation focused on operation of a prototype wave engine with curved channels and on-rotor combustion. Unfortunately, the GE wave engine work is poorly documented in open literature; a short description is given in [54]. Thus, only brief highlights of the GE effort on the wave rotor combustor can be given here.

Schapker at GE conducted a detailed analytical analysis of the wave rotor combustor design in 1958 [55]. The study was divided 
into three main parts: 1) application of the method of characteristics to the solution of a nonsteady duct flow problem, 2) detailed wave diagram computational procedure, and 3 ) loss estimations applied to the previous ideal procedure. This and other in-house analytical efforts assisted in designing and testing a prototype wave engine in 1958-1589 with on-rotor combustion at the California branch. As described by Weber [56], the only test performed on the wave rotor combustor lasted approximately $20 \mathrm{~s}$ when the rotor seized between the end plates. Thermal expansion of the combustion-heated rotor exceeded the tight seal clearances between the rotor and end plates, demonstrating a common difficulty of clearance control between the end plates and rotor. GE continued further testing only on pressureexchange wave rotors [27]. GE's program seems to have been promising and succeeded to a certain extent [54], but in 1963 the company discontinued the development of the wave rotor, reportedly due to changes in business strategy $[54,56]$.

For almost the next three decades, wave rotor development focused on pressure-exchanger machines with no combustion within the rotor channels. Applications included diesel engine supercharging and a wave superheater high-enthalpy wind tunnel for spacecraft reentry simulation [27]. Meanwhile, gas turbine companies focused on refining proven steady-flow technologies until the quest for larger performance gains led again to the wave rotor combustor.

\section{Asea Brown Boveri (1989-1994)}

By the late 1980s, Asea Brown Boveri (ABB) in Switzerland began testing wave rotors for power-generation gas turbine applications with particular attention to wave rotor combustors $[38,39,57,58]$. The interest was backed by ABB's long history in developing and successfully commercializing the Comprex

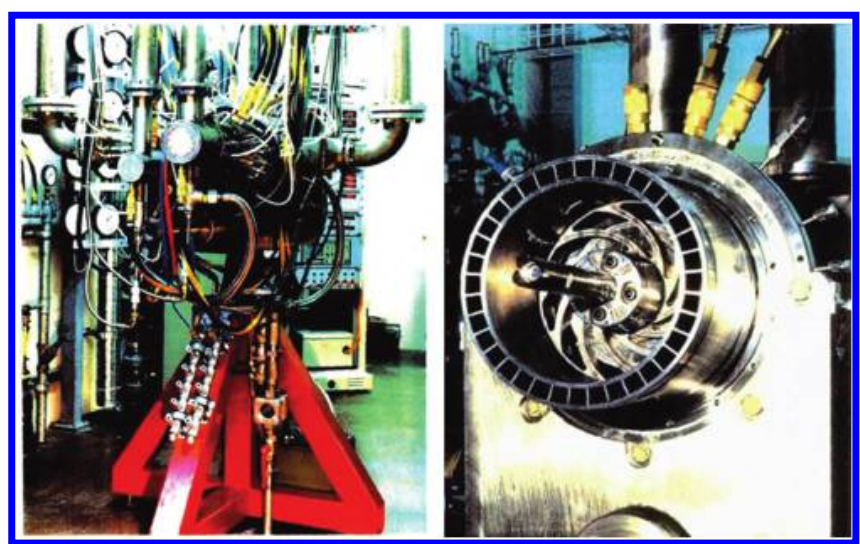

Fig. 9 ABB test rig (left) and rotor subassembly (right) [38]. pressure-wave supercharger for diesel engines through the 1970s and 1980s [27].

In 1989, ABB commenced a three-phase research project to employ the wave rotor concept for gas turbine engines. The first phase of the project from 1989-1991 was aimed at testing a laboratory-scale pressure-exchange wave rotor with external combustion. The demonstrator performance was estimated to allow 17 and $25 \%$ increases in efficiency and specific power, respectively, compared with a baseline engine [31]. These results were consistent with the predictions made later but independently by NASA [28]. The performance encouraged ABB in 1991 to investigate advanced gas turbine systems using a wave rotor combustor. In collaboration with the Swiss Federal Institute of Technology Zurich, a rotaryvalved single-channel wave combustor was built and tested [38]. This $16.5 \mathrm{~cm}$ long, $15 \times 15 \mathrm{~mm}$ cross section, nonrotating channel facilitated optical observation of ignition and constant-volume combustion. Experiments were conducted to address the effects of parameters such as the rotational speed and timing of the valve disks, stoichiometry, pressure, temperature of the air-fuel mixture, and ignition timing. Using a preheated and precompressed air-propane mixture as the working fluid, combustion measurements revealed low $\mathrm{NO}_{x}$ generation, down to $20 \mathrm{ppm}$ in the exhaust gas due to the short residence time $(1-6 \mathrm{~ms})$ with fast deflagrative flame propagation $(15-44 \mathrm{~m} / \mathrm{s})$. This demonstrated the viability of the constant-volume combustion concept using wave rotor principles, as well as the possibility of meeting emissions limits in applying this benefit to commercial power plants and aeroengines.

After testing of the single-channel stationary combustor, the design of a full wave rotor with 36 combustor channels began in 1992 [38,39]. In Fig. 9, pictures of the test rig (left) and the rotor, disks, and shaft (right) are provided. Preserving the previous single-channel geometry, each channel had $16.5 \mathrm{~cm}$ length and $15 \times 15 \mathrm{~mm}$ cross section. The $20-\mathrm{cm}$ inner-diameter rotor was driven by an electric motor capable of up to $5000 \mathrm{rpm}$. Both in the single-channel and 36channel wave rotor engine, spark-plug electric ignition and hot gasinjection ignition methods were used. Figure 10 shows the developed view of this rig where the red and blue-green colors represent the burned and fresh air-fuel mixtures, respectively. The red color is further shaded according to different stoichiometry gases that fed low- and high-pressure outflows for different turbine stages. Operating in two cycles per revolution, each cycle is a mirror image of the other one. This configuration introduces symmetry and assures that both sides of the rotor are washed by the relatively cold-fresh air, avoiding nonuniform temperature distribution in the rotor. Furthermore, the high-pressure and low-pressure outflows allow complete exhaust gas scavenging in one cycle. To start up, two spark plugs with sparking frequency of $3000 \mathrm{~Hz}$ located at each end of the rotor and for each cycle would ignite the combustible mixture in the channels from both sides simultaneously. Self-sustaining ignition was then accomplished by employing axial jet injection of post-

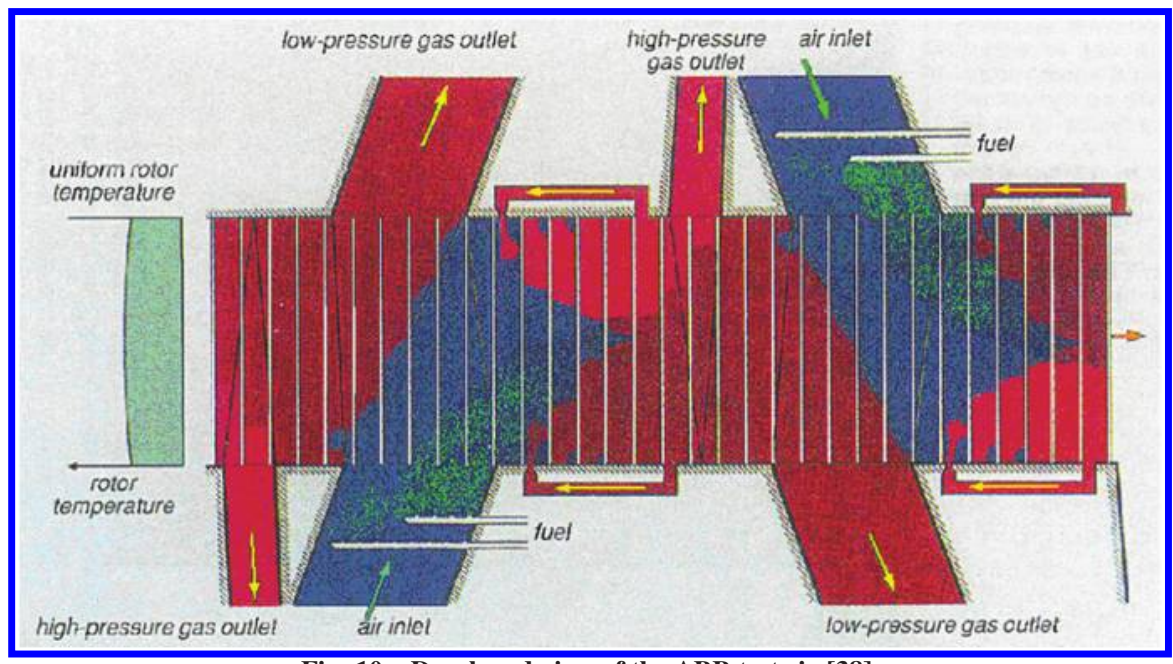

Fig. 10 Developed view of the ABB test rig [ $\underline{38}]$. 
combustion gas from a neighboring channel, as described earlier. Various fuels were tested and the fuel mixtures were stratified using four injection nozzles.

The prototype engine operated successfully until the project was concluded in 1994. During its operation, a number of shortcomings were revealed. They included [38] 1) inhomogeneous mixture in the cell, resulting in a slow diffusion flame, 2) maximum pressure of 9 bar, relative to expected 10-15 bar, presumably due to leakage, which also caused premature ignition and misfiring at higher chamber pressures, 3 ) excess thermal stresses on the ignition ring, 4) inadequate cantilever single-bearing rotor support, 5) complicated and sensitive electromechanical device for controlling leakage gap. Major remedies recommended to make the system better included 1) lead away duct for leakage gas removal, 2) rotor cooling by air, 3) two-sided rotor support, and 4) mechanical control for thermal expansion. These recommendations would necessitate a new rig with major improvements, which was not pursued at the time.

\section{NASA (1994-1997)}

Internal work on pressure-exchange wave rotors and the rapid progress of $\mathrm{ABB}$ encouraged NASA to study wave rotor combustors for possible performance improvements of aircraft propulsion systems. Around 1988, NASA had initiated a comprehensive wave rotor research program at NASA John H. Glenn Research Center at Lewis Field (then Lewis), first using a three-port wave divider machine to study loss mechanisms [59]. A four-port pressureexchange wave rotor was then designed and tested [60]. Also, Paxson developed a wave rotor simulation code with a $\mathbf{Q} 1-\mathrm{D}$ gas dynamic model, to calculate design geometry and off-design wave rotor performance [61]. It was experimentally validated [62] for nonreacting wave rotor flows and is recognized as a general design and analysis tool for wave rotors. Multidimensional simulations [63] examined the role of gradual opening and centrifugal effects on interface skewing. The research effort until 2000 is summarized by Welch [64].

The concept of on-rotor combustion was revisited by Nalim at NASA in 1994, with a computational feasibility assessment of combustion modes in the channels of a wave rotor [42]. Ignition, flame propagation rates in various fuel-oxidant mixtures, and possible wave cycles were studied. Combustion modeling capability was added to the existing Q1-D code to study wave cycles involving both detonation and deflagration modes of combustion [41]. A reaction progress variable was used for uniform mixtures, and multiple species were represented for stratified mixtures, with a oneor two-step reaction. For deflagration modes, mixing-controlled reaction was combined with a simple eddy diffusivity model, ignition-temperature kinetics, and a total-energy-based flammability limit [37]. The performance of detonative and deflagrative cycles was studied by combined gas dynamic and system simulation. It was determined that deflagrative combustion with longitudinal fuel stratification could be accomplished over a reasonable time in wave rotors. The code's one-dimensional detonation prediction capability later became widely useful for the study of pulse detonation engines [20,65]. NASA's internal focus remained on pressure-exchange wave rotors [23], with particular attention to improvements in design, including sealing technology and ducting [35], while sponsoring university research on wave rotor combustion.

Between 1994 and 1998, NASA sponsored an experimental study conducted by Bilgin supervised by Keller (formerly of ABB) [66] at the University of Washington investigating deflagrative combustion initiation of premixed combustion in stationary passages, seeking to quantify hot-gas-jet ignition time. A single-channel rig was built and tested, in which a transient jet of hot gas from a prechamber initiates combustion in the test channel. Distinct features of the flame propagation and combustion process were identified, and an empirical correlation was found based on the optimal Damkohler number. The rig now continues to operate at Indiana UniversityPurdue University Indianapolis (IUPUI), where additional NASAsponsored work was undertaken.

\section{E. Indiana University-Purdue University Indianapolis (1997-Present)}

The Purdue School of Engineering and Technology at IUPUI has conducted a sustained wave rotor research program toward using wave rotor combustors for propulsion and power, with support from Rolls-Royce, NASA, the State of Indiana, and others. Both deflagrative and detonative wave rotors were considered, as were various wave rotor cycles and port and igniter arrangements. For direct thrust generation over a wide Mach number range, the detonative wave rotor [67], which combines PDE and wave rotor technology concepts, was envisioned. A stand-alone detonative rotor, if operable without oxygen enrichment or frequency limitations, can potentially produce about three times the thrust with twice the fuel-specific impulse of a stand-alone deflagrative rotor under subsonic flight conditions for direct thrust applications [68]. Relative to a PDE without exit valving, a wave rotor detonation engine can produce twice as much thrust and pressure gain [44].

Although the detonative wave rotor combustor overcomes some of the challenges of PDEs, its relatively high outflow temperature and velocity remains a cause of poor propulsive efficiency. To address this, Nalim proposed [69] an alternative configuration in which an ejector is integrated into the wave rotor. Known as the rotary wave ejector, the energy and momentum of the detonation is harnessed to admit bypass air downstream of the detonation channels. Numerical modeling indicated [70] that after accounting for flow-turning and shock losses, the specific impulse at static thrust conditions can be doubled compared with the corresponding PDE cycle.

For gas turbine power plants, IUPUI has undertaken analytical modeling, exploration of wave cycles and deflagrative combustion modes, and numerical simulations. Nalim [12] developed a generalized thermodynamic model of pressure-gain combustors, including wave rotor combustors, which determines the thermodynamic limits of confined-combustion processes. This model has been enhanced [71] by combining the thermodynamic model with a gasdynamic model of the flow pattern within the channels using the theory of characteristics and using real gas specific heats.

Nalim [37] also developed fuel stratification strategies in longitudinal and radial [72] directions of rotor channels for improving combustion, emissions and leakage impact. Longitudinal stratification can be arranged by partitioning the inlet duct and modulating a continuous-flow fuel injector to control fuel-air mixture ratio in each segment, similar to $\mathrm{ABB}$, and by direct pilot fuel injection (see Fig. 7). This provides a richer mixture for reliable ignition, lowering $\mathrm{NO}_{x}$ emissions in the leaner main mixture and was modeled for both deflagration [37] and detonation [40] modes. For further benefits from radial partitioning of the rotor channel [72], the rotor channels include circumferential liners that extend a relatively short distance into the length of the channel, as shown in Fig. 11. This arrangement allows the inlet duct to introduce a near-stoichiometric mixture to only the "precombustion chamber" formed between the liners and injects pure air in the regions adjacent the hub and shroud, retaining fuel-lean mixture in the main channel region. The cooler air near the leakage gap substantially reduces leakage gas temperature and thermal loads to the channels and bearings and helps reduce leakage generally by limiting the heating and distortion of the end wall [73]. This technique has not yet been tested experimentally.

Besides simplified quasi-one-dimensional modeling $[37,40,44]$, multidimensional flow simulation was also used to investigate important combustion phenomena, mixing processes, and loss mechanisms, and for experiment design. Two-dimensional simulations have examined flame propagation $[\underline{74}, 75]$, thermal boundary layer response to channel gas flow with varying temperatures [76], and mixture boundary skewing to evaluate ignition and pilot fuel requirements [77].

\section{F. Rolls-Royce (1968-Present) and Joint Rolls-Royce/IUPUI/Purdue} University Program (2000-Present)

Between 1965 and 1972, Rolls-Royce conducted modeling and experimental efforts to develop pressure-exchange wave rotors as 


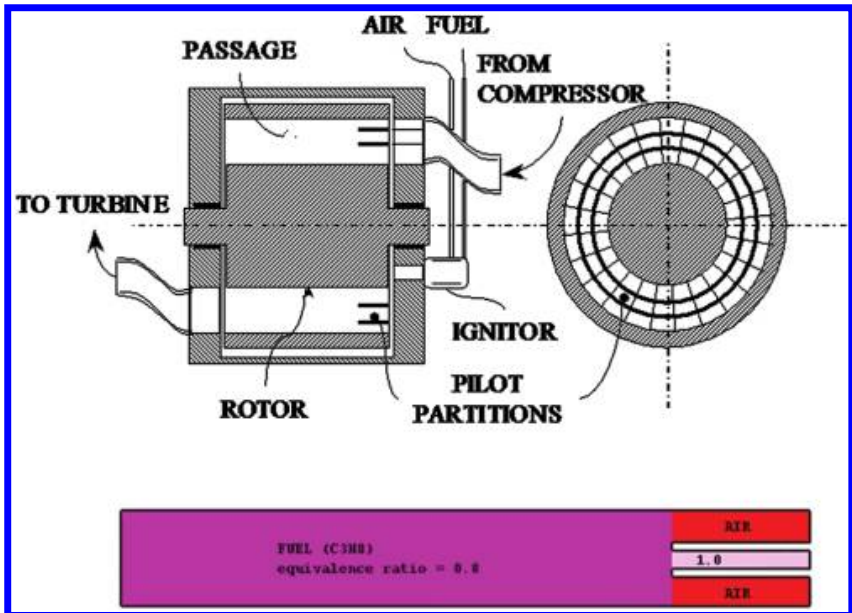

Fig. 11 Stratification of fuel-air mixture by employing partitions (top) and initial fuel distribution in the channel (bottom) [73].

topping spools for gas turbine applications [30,78]. Rolls-Royce also studied turbofan engines using wave rotors with on-rotor combustion. An analytical study predicted a $14 \%$ reduction in specific fuel consumption at sea level and a $10 \%$ reduction at a cruise condition of Mach 0.8 at 35,000 feet altitude [79]. This study encouraged RollsRoyce to perform successful detonations experiments on a rotary shutter-valved stationary multichannel rig around 1968. Company financial difficulties in the 1970s prevented further work [80].

In 1995, Rolls-Royce acquired Allison Engine Company in the United States, which had been collaborating with NASA on toppingcycle wave rotors [32-34]. Pulse detonation engine wave rotors $[81,82]$ were investigated by Rolls-Royce in Indianapolis, Indiana for advanced supersonic turbofan engines [43,79] and subsonic/ supersonic missiles [83]. A feasibility study on using a detonative wave rotor integrated to a supersonic turbofan engine estimated [79] $15 \%$ reduction in specific fuel consumption at sea level and a $\overline{5 \%}$ reduction at a cruise condition of Mach 2.4 at $60,000 \mathrm{ft}$ altitude. For this application, computational flow analysis [43] and mechanical design [79] supported preliminary engine design. A four-port detonation configuration was proposed in which a recirculation duct allows air compressed by the shock of a detonation wave to be reinjected with fuel, as schematically shown at the top of Fig. 12. In collaboration with IUPUI, a relatively uniform profile to the turbine was predicted computationally.

Another study supported by Rolls-Royce revealed [84] advantages and challenges of replacing the conventional combustor of a Rolls-Royce AE3007 high-bypass turbofan engine with the four-port detonative wave rotor. This study defined a regional jet flight mission and linked existing simulation codes. Pressure gain across the modified combustor was estimated from an analytical model developed by Nalim [12]. Mission impact included almost $10 \%$ fuel burn reduction, but approximately a $20 \%$ increase in engine cost, due to the increase in combustor and turbine weights and the new technology. The detonative combustor was estimated to weigh from 175 to $300 \%$ more than the baseline combustor, and turbine weight increased due to higher pressures.

Since 2000, Rolls-Royce has teamed with IUPUI and Purdue University to investigate the combustion process and design of a wave rotor with detonative and near-detonative internal combustion in a demonstrator rig. With initial state government support and company funding, a preliminary design method based on a sequence of computational models [40], a wave rotor combustion test rig, and a new test facility have been developed [85] to design wave processes and test combustion processes in an experimental test rig at Purdue University.

\section{Challenges and Research Needs}

The wave rotor combustor is an unconventional concept with high potential for performance gains for gas turbine engines at a time

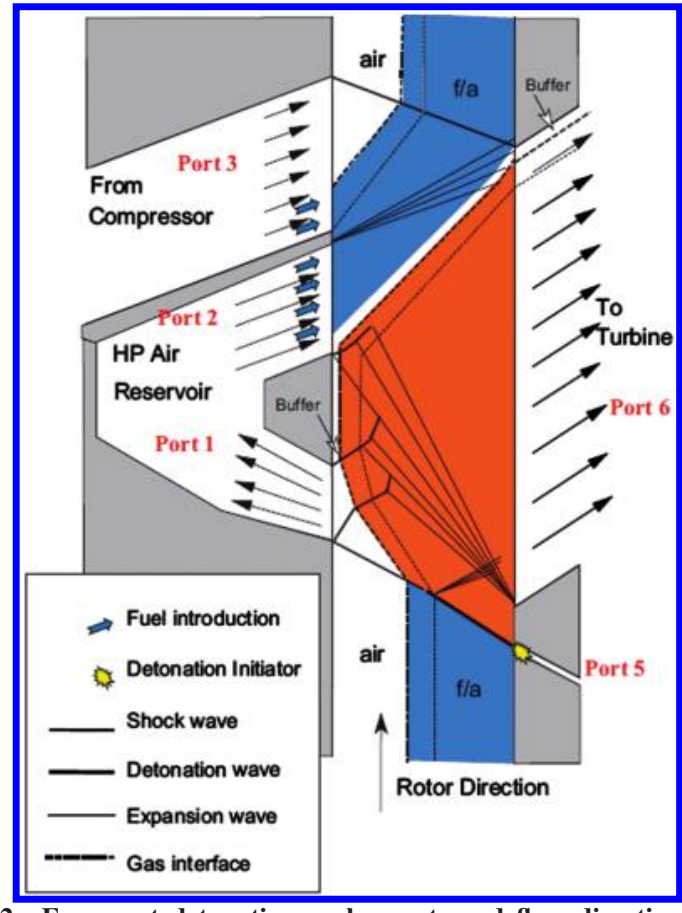

Fig. 12 Four-port detonation cycle: ports and flow direction in the developed view where $f / a$ stands for fuel-air [79].

when fuel costs and carbon emissions have become increasing concerns. Recent research efforts and previous prototypes have demonstrated its feasibility. Today, fast computational tools and fastresponse diagnostics for nonsteady flow and combustion could reveal underlying fundamental physics and potentially shorten development time. New solutions to mechanical design challenges such as clearance control and sealing issues have been developed and are being tested $[\underline{23}, 24,86]$.

As with any new technology, combustion in a wave rotor presents some unique challenges. Basic combustion phenomena, ignition, and control methods remain poorly understood at the fundamental level. Nonsteady combustion in the novel wave rotor geometry involves complex flame-wave interactions fundamentally different from familiar internal combustion engines and steady-flow gas turbine combustion. The interaction of a flame front with strong pressure waves is rare or avoided in conventional combustion systems, other than pulsed devices. Thus, much of the empirical knowledge and models available may not apply to wave rotor combustors.

For small engine combustors, detonative propagation appears unlikely, and fast premixed turbulent combustion processes must be demonstrated in basic experiments. Design for deflagrative combustion is a significant challenge. Combustion is strongly influenced by turbulence $[\underline{38}, 73]$, originating in the upstream compressor, ducting, fuel spray, the opening/closing processes, and shock compression processes and likely to persist over the intake period of a wave cycle [42]. As the large structures break down, their energy reaches scales that promote mixing later in the cycle. Flame fronts are subject to centrifugal acceleration equivalent to thousands of times the gravitational acceleration, with possible benefits. Pressure waves interacting obliquely with flames or other density gradients produce vorticity by baroclinic forces (Richtmyer-Meshkov instability), accelerating or sometimes quenching combustion locally [75]. Energetic and rapid ignition methods, such as hot gas injection at high speed and the use of partitions for thermal management and pilot ignition [73], introduce both complexity and control opportunities. These phenomena interacting together present the greatest uncertainty and motivation for research in developing wave rotor combustion.

For large engine combustors with higher pressure ratios or for direct thrust applications, detonative propagation may be feasible and preferred to minimize cycle time and thus combustor weight. 
Large combustor channel width and high compressor discharge temperature support detonative combustion within specific local fuel-air mixture ratios. Exiting blast waves may be avoided by designs such as shown in Fig. 12, and mixing in the transition duct to any turbine must meet pattern factor requirements. Propagation of a fully developed detonation does not need prior turbulence, but turbulence can aid transition from initially deflagrative propagation. Other methods of generating a detonation may involve multiple ignition sites, external predetonation, or shaped wave interactions. Much of the data on detonations are limited to easily detonable fuels (hydrogen, ethylene), ambient temperature mixtures, and round tubes [36]. Research is needed for other fuels, high inlet temperature conditions typical of gas turbine combustor operation, and rectangular channels.

Finally, the integration of any nonsteady combustion system into a gas turbine or jet engine introduces the challenge of matching oscillatory flow with turbomachinery or an inlet-nozzle system designed for steady flow. Most pulsed combustion devices usually attempt to minimize flow oscillation at the combustor operating frequency by using multiple combustors. The wave rotor combustor additionally and naturally synchronizes multiple combustors to deliver and receive flow in phase-matched ducts, with limited unsteadiness at the much higher channel-passing frequency. Despite accompanying spatial variation, this should allow relatively better integration into current turbine engine and supersonic inlets and nozzles but still introduces mechanical complexity with axially axially nonsymmetric ducting.

To address these issues, sustained and careful experimental efforts should seek better understanding of possible combustion modes and delivered flow quality, applying modern diagnostic techniques that were not available in the past. Experiments should anticipate different combustion modes, depending on fuel specifications, operating conditions, and ignition method. Short duration and lowpressure testing must be followed by tests under real engine conditions and durability studies. Beyond establishing general feasibility of the proposed modes of wave rotor combustion, specific experiments could develop modes that are appropriate for specific applications. For example, military applications seeking expendable high-thrust engines may focus on detonated modes. On the other hand, most commercial and industrial applications would be subject to stringent environmental restrictions that conventional combustion engines were able to accommodate only after decades of painstaking research. It is unlikely that complex emissions, efficiency, and power density trade-offs would become evident in preliminary experiments. Therefore, a long-term realistic approach would focus on achieving stable combustion in an appropriate mode as an initial goal.

Multidimensional simulations of wave rotor flow must elucidate complex features and enable successful design. For instance, the large-scale flow structures generated during the inlet opening processes and nonsteady boundary layer behavior may control mixing of fresh and residual gas [77], with implications for heat loss, cooling, and premature ignition. Thermal management, fuel-air mixture preparation, leakage control, and emissions minimization will benefit from prior detailed computational modeling before designing appropriate experiments. One-dimensional simulations will remain useful for preliminary wave cycle design, bounding performance expectations, and guidance of multidimensional simulation.

For integration with conventional turbomachinery or supersonic inlets and nozzles, studies are needed both at the system level for optimal matching and for the design of transition ducting and layout. Engine development with acceptable risk, resources, and schedule will likely require adaptation of exiting engines rather than the development of a completely new engine. This will apply even stricter constraints on pulsation levels, thermal issues, and dynamic behavior. For example, modern turbines use blade-cooling air from the compressor discharge, but the pressure gain in the wave rotor will necessitate air at the higher turbine inlet pressure level. Fortunately, the wave rotor itself can provide air compression equal to combustion gas compression, but the air extraction must be reliably executed.

\section{Conclusions}

Fuel costs, new research techniques, and technology innovations have provided fresh impetus to consider the unique capabilities of wave rotor devices. The wave rotor combustor is a nonsteady pressure-gain combustion device where the combustion process occurs within the combustion chambers of the rotor, creating deflagrative or detonative combustion modes. The goal of this review was to report the historical and recent progress in this technology and to assess its potential for propulsion and power-generation applications, with close attention to more recent efforts. Although involved researchers may have current and historical knowledge of this technology, it has not reached wider audiences, limiting the opportunity for application ideas. Among various wave rotor applications, interest in gas turbine topping cycles and internal combustion engine supercharging appears to continue, and some new applications have emerged. The wave rotor combustor for gas turbine and ramjet engines has significant potential that is yet unrealized, as indicated by the published work of ABB, NASA, IUPUI, and Rolls-Royce that constitute the major sources of this review.

It is emphasized that there are still many unknowns in the dynamic constant-volume combustion process. Design to meet performance, durability, and environmental goals will influence the choice of combustion modes whether deflagrative or detonative, mixture distribution, ignition methods, and management of resulting pressure waves. This requires further careful experimental efforts on wellinstrumented test rigs. Continued research on sealing and thermal expansion control of the wave rotor combustor and on its integration into turbine engines are also needed to ensure practically useful operation. It is hoped that this review will stimulate wider appreciation and study of this novel technology.

\section{References}

[1] Putnam, A. A., Combustion Driven Oscillations in Industry, Elsevier, New York, 1971.

[2] Azoury, P. H., Engineering Applications of Unsteady Fluid Flow, Wiley, New York, 1992.

[3] Kentfield, J. A. C., Nonsteady, One-Dimensional, Internal, Compressible Flows, Oxford Univ. Press, Oxford, England, U.K., 1993.

[4] Hawthorne, W. R., "Reflections on United Kingdom Aircraft Gas Turbine History," Journal of Engineering for Gas Turbines and Power, Vol. 116, No. 3, 1994, pp. 495-510. doi: $10.1115 / 1.2906848$

[5] Frey, D. N., Klotsch, P., and Egli, A., "The Automotive Free-PistonTurbine Engine," Society of Automotive Engineers, Paper 570051, 1957.

[6] Kentfield, J. A. C., "On the Feasibility of Gas-Turbine Pressure-Gain Combustors," International Journal of Turbo and Jet Engines, Vol. 12, No. 1, 1995, pp. 29-36.

[7] Holzwarth, H., and Junghans, E., "Improvements in Gas Turbines," U.K. Patent No. 20, 546, 1906.

[8] Griepe, A., "Gas Turbine-Engine," U.S. Patent No. 910, 665, 1909.

[9] Hagen, H., "Constant Volume Combustion Gas Turbine with Intermittent Flows," U.S. Patent No. 3, 877, 219, 1975.

[10] Gertz, A., "Gas Turbine Engine," U.S. Patent No. 4, 241, 576, 1980.

[11] Zdvorak, E. H., "Constant Volume Combustion Turbine with Plurality Flow Turbine Wheels," U.S. Patent No. 5, 960, 625, 1998.

[12] Nalim, M. R., "Thermodynamic Limits of Work and Pressure Gain in Combustion and Evaporation Processes," Journal of Propulsion and Power, Vol. 18, No. 6, 2002, pp. 1176-1182. doi: $10.2514 / 2.6076$

[13] Heiser, W. H. and Pratt, D., "Thermodynamic Cycle Analysis of Pulse Detonation Engines," Journal of Propulsion and Power, Vol. 18, No. 1, 2002, pp. 68-76. doi: $10.2514 / 2.5899$

[14] Nicholls, J. A., Wilkinson, H. R., and Morrison, R. B., "Intermittent Detonation as a Thrust-Producing Mechanism," Jet Propulsion, Vol. 27, No. 5, 1957, pp. 534-541.

[15] Kailasanath, K., "Review of Propulsion Applications of Detonation 
Waves," AIAA Journal, Vol. 38, No. 9, 2000, pp. 1698-1708. doi: $10.2514 / 2.1156$

[16] Kailasanath, K., "Recent Developments in the Research on Pulse Detonation Engines," AIAA Journal, Vol. 41, No. 2, 2003, pp. 145-159. doi: $10.2514 / 2.1933$

-117] Roy, G. D., Frolov, S. M., Borisov, A. A., and Netzar, D. W., "Pulse Detonation Propulsion: Challenges, Current Status, and Future Perspective," Progress in Energy and Combustion Science, Vol. 30, No. 6, 2004, pp. 545-672.

doi:10.1016/j.pecs.2004.05.001

[18] Bussing, T. R. A., "Rotary Valve Multiple Combustor Pulse Detonation Engine," U.S. Patent No. 5, 345, 758, 1994.

[19] Wu, Y., Ma, F., and Yang, V., "System Performance and Thermodynamic Cycle Analysis of Air-Breathing Pulse Detonation Engines," Journal of Propulsion and Power, Vol. 19, No. 4, 2003, pp. 556-567. doi: $10.2514 / 2.6166$

[20] Paxson, D. E., "Performance Evaluation Method for Ideal Airbreathing Pulse Detonation Engines," Journal of Propulsion and Power, Vol. 20, No. 5, 2004, pp. 945-947. doi: $10.2514 / 1.11426$

[21] Xia, G., Li, D., and Merkle, C., "Modeling of Pulsed Detonation Tubes in Turbine Systems," AIAA Paper 2005-0225, 2005.

[22] Rasheed, A., Furman, A. H., and Dean, A. J., "Interactions Pressure Measurements and Attenuation in a Hybrid Multitube Pulse Detonation Turbine System," Journal of Propulsion and Power, Vol. 25, No. 1, 2009, pp. 148-161. doi: $10.2514 / 1.31893$

[23] Wilson, J., Welch, G. E., and Paxson, D. E., "Experimental Results of Performance Tests on a Four-Port Wave Rotor," AIAA Paper 20071250, 2007.

[24] Hendricks, R. C., Wilson, J., Wu, T., and Flower, R., "Bidirectional Brush Seals," American Society of Mechanical Engineers, Paper 97GT-256, 1997.

[25] Berchtold, M., "The Comprex®, Proceeding ONR/NAVAIR Wave Rotor Research and Technology Workshop, Rept. NPS-67-85-008, Naval Postgraduate School, Monterey, CA, 1985, pp. 50-74

[26] Shreeve, R. P., and Mathur, A., Proceeding ONR/NAVAIR Wave Rotor Research and Technology Workshop, Rept. NPS-67-85-008, Naval Postgraduate School, Monterey, CA, 1985.

[27] Akbari, P., Nalim, M. R., and Müller, N., "A Review of Wave Rotor Technology and Recent Developments," Journal of Engineering for Gas Turbines and Power, Vol. 128, No. 4, 2006, pp. 717-735. doi:10.1115/1.2204628

[28] Welch, G. E., Jones, S. M., and Paxson, D. E., "Wave Rotor-Enhanced Gas Turbine Engines," Journal of Engineering for Gas Turbines and Power, Vol. 119, No. 2, 1997, pp. 469-477. doi:10.1115/1.2815598

[29] Fatsis, A., and Ribaud, Y., "Thermodynamic Analysis of Gas Turbines Topped with Wave Rotors," Aerospace Science and Technology, Vol. 3, No. 5, 1999, pp. 293-299. doi:10.1016/S1270-9638(00)86965-5

[30] Akbari, P., Müller, N., and Nalim, M. R., "Performance Enhancement of Microturbine Engines Topped with Wave Rotors," Journal of Engineering for Gas Turbines and Power, Vol. 128, No. 1, 2006, pp. 190-202 doi:10.1115/1.1924484

[31] Zauner, E., Chyou, Y. P., Walraven, F., and Althaus, R., "Gas Turbine Topping Stage Based on Energy Exchangers: Process and Performance," American Society of Mechanical Engineers, Paper 93-GT-58, 1993.

[32] Gegg, S., and Snyder, P. H., "Aerodynamic Design of a Wave Rotor to High Pressure Turbine Transition Duct," AIAA Paper 98-3249, 1998.

[33] Weber, K., and Snyder, P. H., "Wave Rotor to Turbine Transition Duct Flow Analysis," AIAA Paper 98-3250, 1998.

[34] Snyder, P. H. and Fish, R. E., "Assessment of a Wave Rotor Topped Demonstrator Gas Turbine Engine Concept," American Society of Mechanical Engineers, Paper 96-GT-41, 1996.

[35] Welch, G. E., Slater, J. W., and Wilson, J., "Wave-Rotor Transition Duct Experiment," AIAA Paper 2007-1249, 2007.

[36] Nalim, M. R., and Pekkan, K., "Internal Combustion Wave Rotors for Gas Turbine Engine Enhancement," American Society of Mechanical Engineers, Paper IGTC-2003-FR-303, 2003.

[37] Nalim, M. R., "Longitudinally Stratified Combustion in Wave Rotors," Journal of Propulsion and Power, Vol. 16, No. 6, 2000, pp. 1060-1068. doi: $10.2514 / 2.5676$

[38] Weber, R., "A Pressure-Wave Machine with Integrated ConstantVolume Combustion," Swiss Energy Research Report 1977-1997, National Foundation of Energy Research, Switzerland, Project No. 426,
1997, pp. 142-153.

[39] Walraven, F., "Operational Behavior of a Pressure Wave Machine with Constant Volume Combustion," Asea Brown Boveri, Technical Rept. CHCRC 94-10, 1994.

[40] Akbari, P., Nalim, M. R., and Snyder, P. H., "Numerical Simulation and Design of a Combustion Wave Rotor for Deflagrative and Detonative Propagation," AIAA Paper 2006-5134, 2006.

[41] Nalim, M. R., and Paxson, D. E., "A Numerical Investigation of Premixed Combustion in Wave Rotors," Journal of Engineering for Gas Turbines and Power, Vol. 119, No. 3, 1997, pp. 668-675. doi: $10.1115 / 1.2817036$

[42] Nalim, M. R., "Assessment of Combustion Modes for Internal Combustion Wave Rotors," Journal of Engineering for Gas Turbines and Power, Vol. 121, No. 2, 1999, pp. 265-271. doi: $10.1115 / 1.2817116$

[43] Snyder, P. H., Alparslan, B., and Nalim, M. R., "Gas Dynamic Analysis of the Constant Volume Combustor, A Novel Detonation Cycle," AIAA Paper 2002-4069, 2002.

[44] Akbari, P., and Nalim, M. R., "Analysis of Flow Processes in Detonative Wave Rotors and Pulse Detonation Engines," AIAA Paper 2006-1236, 2006.

[45] Foa, J. V., Elements of Flight Propulsion, Wiley, New York, 1960.

[46] Lewis, B. R., "Engine Having a Rotor with a Plurality of Circumferentially_Spaced Combustion Chambers," U.S. Patent No. 2, 705, 867, 1955

[47] Wilson, D. G., "Wave Rotors as Substitutes for Gas-Turbine DiffuserCombustor Systems," Proceeding ONR/NAVAIR Wave Rotor Research and Technology Workshop, Rept. NPS-67-85-008, Naval Postgraduate School, Monterey, CA, 1985, pp. 250-262.

[48] Hertzberg, A., and Logan, G. J., "A New Form of Heat Engine Utilizing Pressure Waves," Cornell Aeronautical Lab, Inc., Project SQUID Technical Memorandum No. CAL-35, Buffalo, NY, 1951.

[49] Schmidt, F. A. F., "Mechanically Controlled Multistage Combustion Chambers for Gas-Impulse-Type Engines and Improved Discharged Control Therefor," U.S. Patent No. 2, 937, 498, 1960.

[50] Spalding, D. B., "Pressure Exchangers," U.S. Patent No. 2, 940, 656, 1960.

[51] Spalding, D. B., "Combustion Ignition Pressure Exchanger," U.S. Patent No. 3, 003, 315, 1961

[52] Goldstein, A. W., Klapproth, J. F., and Hartmann, M. J., "Ideal Performance of Valved-Combustors and Applicability to Several Engine Types," Transactions of the American Society of Mechanical Engineers, Vol. 80, July 1958, pp. 1027-1036.

[53] Zipkin, M. A., and Lewis, G. W., "Analytical and Experimental Performance of an Explosion-Cycle Combustion Chamber for a JetPropulsion Engine," NACA, Technical Note 1702, Washington, D.C., 1948.

[54] Mathur, A., "A Brief Review of the GE Wave Engine Program (19581963)," Proceeding ONR/NAVAIR Wave Rotor Research and Technology Workshop, Rept NPS-67-85-008, Naval Postgraduate School, Monterey, CA, 1985, pp. 171-193.

[55] Schapker, L. R., "Analysis of a Wave Combustor Designed for TimeSteady Inlet and Discharge Conditions," General Electric Co., Rept. No. DF58AGT387, 1958.

[56] Weber, H. E., Shock Wave Engine Design, Wiley, New York, 1995.

[57] Keller, J. J., "Gas Turbine With a Pressure Wave Machine as the High Pressure Compressor Part," U.S. Patent No. 4, 719, 746, 1988.

[58] Keller, J. J., "Pressure Wave Machine with Constant-Volume Combustion as a Superstage for Gas Turbines," Asea Brown Boveri, Technical Rept. CRBT 90-20, 1990.

[59] Wilson, J., "An Experimental Determination of Losses in a Three-Port Wave Rotor," Journal of Engineering for Gas Turbines and Power, Vol. 120, No. 4, 1998, pp. 833-842. doi: $10.1115 / 1.2818476$

[60] Wilson, J., "Design of the NASA Lewis 4-Port Wave Rotor Experiment," AIAA Paper 97-3139, 1997.

[61] Paxson, D. E., "Numerical Simulation of Dynamic Wave Rotor Performance," Journal of Propulsion and Power, Vol. 12, No. 5, 1996, pp. 949-957. doi: $10.2514 / 3.24127$

[62] Paxson, D. E., "Comparison Between Numerically Modeled and Experimentally Measured Wave-Rotor Loss Mechanism," Journal of Propulsion and Power, Vol. 11, No. 5, 1995, pp. 908-914.

[63] Welch, G. E., "Two-Dimensional Computational Model for Wave Rotor Flow Dynamics," Journal Engineering for Gas Turbines and Power, Vol. 119, No. 4, 1997, pp. 978-985. doi:10.1115/1.2817086

[64] Welch, G. E., "Overview of Wave-Rotor Technology for Gas Turbine Engine Topping Cycles," Novel Aero Propulsion Systems International 
Symposium, The Institution of Mechanical Engineers, London, 2000, pp. 2-17.

[65] Paxson, D. E., and Perkins, H. D., "Thermal Load Considerations for Detonative Combustion-Based Gas Turbine Engines," AIAA Paper 2004-3396, 2004.

[66] Bilgin, M., Keller, J. J., and Breidenthal, R. E., "Ignition and Flame Propagation Process with Rotating Hot Jets in a Simulated Wave Engine Test Cell," AIAA Paper 98-3399, 1998.

[67] Nalim, M. R., "Wave Rotor Detonation Engine," U.S. Patent No. 6, 460, 342, 2002.

[68] Nalim, M. R., and Jules, K., "Pulse Combustion and Wave Rotors for High-Speed Propulsion Engines," AIAA Paper 98-1614, 1998.

[69] Nalim, M. R., "Rotary Ejector Enhanced Pulsed Detonation System and Method," U.S. Patent No. 6, 845, 620, 2005.

[70] Geng, T., and Nalim, M. R., "Statistical Design-of-Experiments for Wave Ejector Performance Improvement," AIAA Paper 2004-1211, 2004.

[71] Nalim, M. R., Li, H., and Akbari, P., "Air-Standard Aerothermodynamic Analysis of Gas Turbine Engines with Wave Rotor Combustion," Journal of Engineering for Gas Turbines and Power, 2009 (to be published).

[72] Nalim, M. R., "Partitioned Multi-Channel Combustor," U.S. Patent No. 6, 526, 936, 2003.

[73] Pekkan, K., and Nalim, M. R., "Two-Dimensional Flow and NOx Emissions in Deflagrative Internal Combustion Wave Rotor Configurations," Journal of Engineering for Gas Turbines and Power, Vol. 125, No. 3, 2003, pp. 720-733. doi: $10.1115 / 1.1586315$

[74] Baronia, D., Nalim, M. R., and Akbari, P., "Numerical Study of Wave Rotor Ignition and Flame Propagation in a Single-Channel Rig," AIAA Paper 2007-5054, 2007.

[75] Kilchyk, V., Merkle, C., and Nalim, M. R., "Effect of Channel Rotation on the Turbulent Combustion Rates Attained in the Wave Rotor Combustor," AIAA Paper 2007-5053, 2007.
[76] Li, H., and Nalim, M. R., "Thermal Boundary Layer Response to Convected Far-Field Flow Temperature Changes," Journal of Heat Transfer, Vol. 130, No. 10, 2008, pp. 101001-101006. doi:10.1115/1.2953239

[77] Banerjee, A., Khalid, A., Akbari, P., and Nalim, M. R., "TwoDimensional Numerical Modeling of Mixture Inflow in a Combustion Wave Rotor," AIAA Paper 2006-4125, 2006.

[78] Moritz, R., "Rolls-Royce Study of Wave Rotors (1965-1970)," Proceeding ONR/NAVAIR Wave Rotor Research and Technology Workshop, Rept. NPS-67-85-008, Naval Postgraduate School, Monterey, CA, 1985, pp. 116-1124.

[79] Smith, C. F., Snyder, P. H., Emmerson, C. W., and Nalim, M. R., "Impact of the Constant Volume Combustor on a Supersonic Turbofan Engine," AIAA Paper 2002-3916, 2002.

[80] Kentfield, J. A. C., "Wave Rotors and Highlights of Their Development," AIAA Paper 98-3248, 1998.

[81] Snyder, P. H., "Pulse Detonation Engine Wave Rotor," U.S. Patent No. 6, 449, 939, 2002.

[82] Snyder, P. H., and Emmerson, C. W., "Constant Volume Combustor," U.S. Patent No. 7, 137, 243, 2006.

[83] Baker, V. D., "Propulsion Module," U.S. Patent No. 6, 584, 764, 2003.

[84] Won, H. T., and Waters, M., "Control Constant Volume Combustor Implementation on a 50 Passenger Commercial Regional Transport Mission Simulation," AIAA Paper 2003-4413, 2003.

[85] Matsutomi, Y., Hein, C., Lian, C., Meyer, S., and Heister, S., "Facility Development for Testing of Wave Rotor Combustion Rig," AIAA Paper 2007-5052, 2007.

[86] Akbari, P., Nalim, M. R., Donovan, E. C., and Snyder, P. H., "Leakage Assessment of Pressure-Exchange Wave Rotors," Journal of Propulsion and Power, Vol. 24, No. 4, 2008, pp. 732-740. doi: $10.2514 / 1.31725$

J. Powers Associate Editor 
This article has been cited by:

1. E. Lutoschkin, M. G. Rose, S. Staudacher. 2013. Pressure-Gain Combustion Using Shock-Flame Interaction. Journal of Propulsion and Power 29:5, 1181-1193. [Abstract] [Full Text] [PDF] [PDF Plus]

2. Abdullah Karimi, Prasanna Chinnathambi, Manikanda K. Rajagopal, Mohamed R. NalimHot Jet Re-ignition of Hydrocarbons and Hydrogen in Air: Effect of Jet Chemical Activity . [Citation] [PDF] [PDF Plus]

3. V. Kilchyk, R. Nalim, C. Merkle. 2013. Scaling Interface Length Increase Rates in Richtmyer-Meshkov Instabilities. Journal of Fluids Engineering 135:3, 031203. [CrossRef]

4. Sameera Wijeyakulasuriya, Tarek Elharis, Mohamed NalimFuel Proximity Effect on Hot-Jet Ignition in a Wave Rotor Constant Volume Combustor . [Citation] [PDF] [PDF Plus]

5. G. Sun, Pezhman Akbari, B. Gower, Norbert MuellerThermodynamics of the Wave Disk Engine . [Citation] [PDF] [PDF Plus]

6. Vineet Kumar, Pratikash Panda, Hukam Mongia, Sameer NaikInnovative Approaches for Reducing CO2 Emissions of Aviation Engines Part 1: Selection of Promising Approaches . [Citation] [PDF] [PDF Plus]

7. M. R. Nalim, Z. A. Izzy, P. Akbari. 2012. Rotary wave-ejector enhanced pulse detonation engine. Shock Waves 22:1, 23-38. [CrossRef]

8. Frank Lu, Eric Braun, Luca Massa, Donald WilsonRotating Detonation Wave Propulsion: Experimental Challenges, Modeling, and Engine Concepts (Invited) . [Citation] [PDF] [PDF Plus]

9. V. Kilchyk, R. Nalim, C. Merkle. 2011. Laminar premixed flame fuel consumption rate modulation by shocks and expansion waves. Combustion and Flame 158:6, 1140-1148. [CrossRef]

10. Indika Perera, Sameera Wijeyakulasuriya, Razi NalimHot Combustion Torch Jet Ignition Delay Time for Ethylene-Air Mixtures . [Citation] [PDF] [PDF Plus] 